\title{
Piperazine sulfonamides as DPP-IV inhibitors: Synthesis, induced-fit docking and in vitro biological evaluation
}

\author{
REEMA ABU KHALAF* \\ EBTISAM ALWARAFI \\ DIMA SABBAH \\ Department of Pharmacy, Faculty \\ of Pharmacy, Al-Zaytoonah University \\ of Jordan, Amman, Jordan
}

Accepted October 20, 2020

Published online December 23, 2020

\begin{abstract}
Diabetes mellitus is a chronic illness that needs persistent medical attention and continuous patient self-management to avoid acute complications. Dipeptidyl peptidase-IV (DPP-IV) inhibitors minimize glucagon and blood glucose levels by increasing the incretin levels, glucagon-like peptide (GLP-1) and glucose-dependent insulinotropic polypeptide (GIP), leading to insulin secretion from pancreatic beta cells. In the present study, nine 1,4-bis(phenylsulfonyl) piperazine derivatives $1 \mathbf{a}-\mathbf{i}$ were synthesized and identified using ${ }^{1} \mathrm{H}$ NMR, ${ }^{13} \mathrm{C}$ NMR, MS and IR spectroscopies. These compounds were tested in vitro and showed inhibitory activity ranging from 11.2 to $22.6 \%$ at $100 \mu \mathrm{mol} \mathrm{L}^{-1}$ concentration. Piperazine sulfonamide derivatives were found to be promising DPP-IV inhibitors, where the presence of electron-withdrawing groups such as $\mathrm{Cl}(\mathbf{1} \mathbf{a}-\mathbf{c})$ improved the activity of the compounds more than electrondonating groups such as $\mathrm{CH}_{3}(\mathbf{1} \mathbf{d}-\mathbf{f})$ at the same position. Additionally, meta-substitution is disfavored $(\mathbf{1 b}, \mathbf{1 e}, \mathbf{1 g})$. Induced-fit docking studies suggested that the targeted compounds 1a-i occupy the binding domain of DPP-IV and form H-bonding with the backbones of R125, E205, E206, F357, K554, W629, Y631, Y662 and R669.
\end{abstract}

Keywords: piperazine sulfonamide, dipeptidyl peptidase-IV inhibitor, diabetes mellitus, induced-fit docking

Diabetes mellitus (DM) became a rising epidemic in the last century. It is one of the leading causes of death worldwide (1). About 451 million people had diabetes in 2017 and the number is expected to become greater than 693 million by 2045 (2). Reduced insulin secretion, tissue resistance to insulin, or both, are considered as common factors for DM development (3).

Piperazine-containing compounds were found to exert different pharmacological activities, including preserving memory in animal models of Alzheimer's disease (4),

\footnotetext{
*Correspondence; e-mail: reema.abukhalaf@zuj.edu.jo; rima_abu_khalaf@yahoo.com
} 
$\alpha$-amylase inhibitory activity (5), antibacterial, antifungal activity (6), antiplasmodial activity (7), and HIV-1 protease inhibition (8).

Dipeptidyl peptidase-IV (DPP-IV) enzyme is a plasma soluble enzyme found in the capillary bed of the gut mucosa. Other organs such as the kidney, intestine and liver are announced to have DPP-IV enzyme. It is related to the serine proteases family and exists as a homodimer containing 766 amino acids with Asp-His-Ser at the active site. DPP-IV structure has a $\beta$-propeller domain and an $\alpha / \beta$-hydrolase domain, where the catalytic peptidase function takes place (9). It removes the proline and alanine from the $N$-terminal ends of glucagon-like peptide (GLP-1) and glucose-dependent insulinotropic polypeptide (GIP) making them biologically inactive. Some substrates with glycine, valine, serine or leucine can be cleaved at a slower rate, however, the enzyme is unable to cleave substrates with proline in position 3 (10). DPP-IV comprises hydrophobic S1 and S2 pockets (which contain Arg125, Ser209, Phe357, Arg358, Tyr547, Ser631, Val656, Trp659, Tyr62, Tyr666, Asn710, and Val711) and S3 (Asn281, Leu294, Leu340, Val341, Ala342, and Arg343) which is an alternative binding site and is considered to be an allosteric binding site (11). Hydrophobic amino acids at the N-terminal of the enzyme (Glu205, Glu206 and Tyr662) are thought to increase the DPP-IV substrate specificity (12).

DPP-IV inhibitors were developed as oral antidiabetic drugs that control the blood glucose level by prohibiting the degradation of incretin hormones GLP-1 and GIP, which successfully promotes insulin secretion, inhibits glucagon release and enhances glucose control in patients with type $2 \mathrm{DM}$ (13). The major representatives of this class are sitagliptin, vildagliptin, saxagliptin, teneligliptin, linagliptin, and alogliptin (14-20). Sitagliptin is a triazolopiperazine derivative (Fig. 1) containing amino and amide moieties (15). It is the first gliptin to be FDA approved (October 2006) and the recommended dose is $100 \mathrm{mg}$ once a day (16).

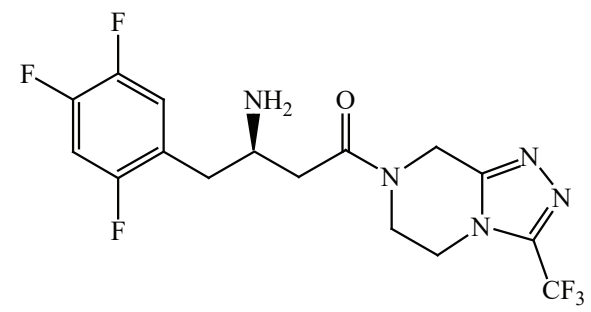

Fig. 1. Chemical structure of the DPP-IV inhibitor sitagliptin.

Earlier, our research group designed and synthesized different potential DPP-IV inhibitors such as: $N^{4}$-sulfonamido succinamic, phthalamic, acrylic and benzoyl acetic acid derivatives (21), acridines (22), sulfamoyl-phenyl acid esters (23), and phenanthridine amides (24). This work reports the synthesis of 1,4-bis(phenylsulfonyl) piperazine derivatives 1a-i, as potential DPP-IV inhibitors. The target compounds were developed based on the presence of structural features similar to those present in sitagliptin, which are the piperazine ring, benzene rings and sulfonamide moiety instead of the carboxamide group. Furthermore, some of the prepared compounds were fluorinated. 


\section{EXPERIMENTAL}

\section{Materials and methods}

Piperazine, 2-chlorophenylsulfonyl chloride and 3-chlorophenylsulfonyl chloride were purchased from Acros (Belgium), whereas 4-chlorophenylsulfonyl chloride, 2-tosylsulfonyl chloride, 3-tosylsulfonyl chloride, 4-tosylsulfonyl chloride, 3,5-difluorophenylsulfonyl chloride, 2,6-difluorophenylsulfonyl chloride and 4-(trifluoromethyl)phenylsulfonyl chloride were purchased from Sigma-Aldrich (USA). Triethylamine, acetone, and dichloromethane $\left(\mathrm{CH}_{2} \mathrm{Cl}_{2}\right)$ were purchased from Tedia (USA). Solvents were used in the experiments without further purification.

Melting points were measured using the Gallenkamp melting point apparatus (Gallenkamp, UK) and were uncorrected. Infrared spectra were measured using the Shimadzu IR Affinity-1 spectrophotometer (Shimadzu, Japan). The samples were prepared as thin solid films using potassium bromide discs (Acros). NMR was recorded on Bruker $500 \mathrm{MHz}$ AvanceIII (USA). The samples were dissolved in deuterated dimethyl sulfoxide (DMSO) for compounds $\mathbf{1 a}-\mathbf{c}, \mathbf{1 g}$ and $\mathbf{1 h}$, or in deuterated chloroform $\left(\mathrm{CDCl}_{3}\right)$ for compounds $\mathbf{1 d}-\mathbf{f}$ and 1i. Mass spectra were recorded on Bruker Apex-IV (USA).

Pre-coated TLC plates dimension $20 \times 20 \mathrm{~cm}, 0.25 \mathrm{~mm}$ silica gel 60 with fluorescent indicator under $254 \mathrm{~nm}$ (Macherey-Nagel, Germany) were used. AFLX800TBI microplate fluorimeter (BioTek Instruments, Winooski, VT, USA) was used for the in vitro bioassay. Column chromatography on silica gel stationary phase of high-purity grade, pore size 60

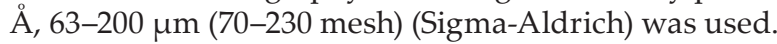

\section{Synthesis of 1,4-bis(phenylsulfonyl) piperazine derivatives $\mathbf{1 a - i}$}

Compounds $1 \boldsymbol{a}-\boldsymbol{e}, \mathbf{1 g}$ and $\mathbf{1 h}$. - To piperazine (0.5 g, $5.8 \mathrm{mmol})$ in acetone $(5 \mathrm{~mL}), 12.8$ mmol of one of the substituted phenylsulfonyl chlorides: 2-chlorophenylsulfonyl chloride, 3-chlorophenylsulfonyl chloride, 4-chlorophenylsulfonyl chloride, 2-tosylsulfonyl chloride, 3-tosylsulfonyl chloride, 3,5-difluorophenylsulfonyl chloride or 2,6-difluorophenylsulfonyl chloride, was slowly added with cooling. The solution of $\mathrm{NaOH}(0.51 \mathrm{~g}, 12.8 \mathrm{mmol})$ in water $(5 \mathrm{~mL})$ was added to the previous mixture. This resulted in an exothermic reaction and a precipitate was immediately formed. Once the exothermic reaction had ceased, the reaction mixture was heated at reflux for $1.5 \mathrm{~h}$. The precipitate which formed was filtered and washed with abs. ethanol $(2 \times 10 \mathrm{~mL})$ and water $(2 \times 10 \mathrm{~mL})$. The obtained powder was dried in the oven to get the targeted compounds: 1,4-bis(2-chlorophenylsulfonyl) piperazine (1a), 1,4-bis(3-chlorophenylsulfonyl) piperazine (1b), 1,4-bis(4-chlorophenylsulfonyl) piperazine (1c), 1,4-bis(2-tosylsulfonyl) piperazine (1d) (27), 1,4-bis(3-tosylsulfonyl) piperazine (1e), 1,4-bis(3,5-difluorophenylsulfonyl) piperazine (1g) or 1,4-bis(2,6-difluorophenylsulfonyl) piperazine (1h) (28).

Compounds 1 f and 1i. - Twenty mmol of 4-tosylsulfonyl chloride or 4-(trifluoromethyl) phenylsulfonyl chloride was dissolved in $\mathrm{CH}_{2} \mathrm{Cl}_{2}(40 \mathrm{~mL})$ in an ice bath and piperazine (10 mmol, $0.861 \mathrm{~g})$ was added. Then, triethylamine $(20 \mathrm{mmol}, 2.786 \mathrm{~mL})$ was added. The reaction mixture was stirred at room temperature for $48 \mathrm{~h}$ and then extracted with $\mathrm{HCl}$ solution $(\mathrm{pH}=3)$. The $\mathrm{CH}_{2} \mathrm{Cl}_{2}$ layer was dried over anhydrous $\mathrm{Na}_{2} \mathrm{SO}_{4}$ and filtered. The solvent was evaporated. After evaporation of the solvent, the residue of 1,4-bis(4-tosylsulfonyl) 
piperazine (1f) (27) or 1,4-bis(4-(trifluoromethyl)phenylsulfonyl) piperazine (1i), was purified by column chromatography eluting with $\mathrm{CH}_{2} \mathrm{Cl}_{2}$.

\section{In vitro DPP-IV inhibition bioassay}

In vitro evaluation of DPP-IV inhibitory activity of the synthesized compounds was carried out using a commercially available kit [BioVision DPP-IV Inhibitor Screening Kit (fluorometric), USA]. In BioVision's DPP-IV inhibitor screening kit, DPP-IV cleaves a substrate (H-Gly-Pro-AMC) to release a quenched fluorescent group, AMC (7-amino-4-methyl coumarin), $(\mathrm{Ex} / \mathrm{Em}=360 / 460 \mathrm{~nm})$. In presence of a DPP-IV inhibitor, the cleavage will be inhibited. Sitagliptin is included as a control inhibitor.

Two milligrams of the tested inhibitor (1a-i) were dissolved in DMSO to prepare the stock solution $\left(10 \mathrm{mmol} \mathrm{L}^{-1}\right)$. Serial dilution of stock solution was carried out to prepare the final solution $\left(400 \mu \mathrm{mol} \mathrm{L}^{-1}\right)$, out of which $25 \mu \mathrm{L}$ was transferred to the 96-well plate and diluted 4 times to afford the final concentration of $100 \mu \mathrm{mol} \mathrm{L} \mathrm{L}^{-1}$ in the well. The $25 \mu \mathrm{L}$ of the tested inhibitor (or sitagliptin) was mixed well with $50 \mu \mathrm{L}$ of the DPP-IV enzyme and incubated for 10 minutes at $37^{\circ} \mathrm{C}$. Then, $25 \mu \mathrm{L}$ of the DPP-IV substrate was added, mixed well and incubated for 30 minutes. Blanks were prepared in the absence of the DPP-IV enzyme, where $50 \mu \mathrm{L}$ of the assay buffer was used instead.

\section{Computational research}

Preparation of protein structure. - The X-ray coordinates of DPP-IV (PDB ID: 4A5S) (25) were adopted from the RCSB Protein Data Bank (PDB). The coordinates were prepared and energetically minimized using the protein preparation (26) module in the Schrödinger enterprise to maximize $\mathrm{H}$-bond interactions.

Preparation of ligand structures. - Structures of synthesized compounds (ligands) were modeled on the template of co-crystalized ligand (N7F) in 4A5S. The ligands were built using MAESTRO (26) build algorithm and subjected to energy minimization by MacroModel wizard employing the OPLS2005 force field.

Induced-fit docking (IFD). - The co-crystallized ligand N7F was identified as a centroid in the 4A5S binding domain. The van der Waals scaling factors for receptor and ligand were adjusted to 0.5 to permit enough flexibility for the best-docked ligand pose. Other parameters were calibrated as default. The ligand conformation with the highest XP Glide score was selected (26).

\section{RESULTS AND DISCUSSION}

\section{Chemistry}

The reaction of piperazine with various substituted sulfonyl chlorides, 2-chlorophenylsulfonyl chloride, 3-chlorophenylsulfonyl chloride, 4-chlorophenylsulfonyl chloride, 2-tosylsulfonyl chloride, 3-tosylsulfonyl chloride, 4-tosylsulfonyl chloride, 3,5-difluorophenylsulfonyl chloride, 2,6-difluorophenylsulfonyl chloride or 4-(trifluoromethyl)phenylsulfonyl chloride, in acetone, produced six novel compounds; $\mathbf{1 a}, \mathbf{1 b}, \mathbf{1 c}, \mathbf{1 e}, \mathbf{1 g}$, and $\mathbf{1 i}$, and 


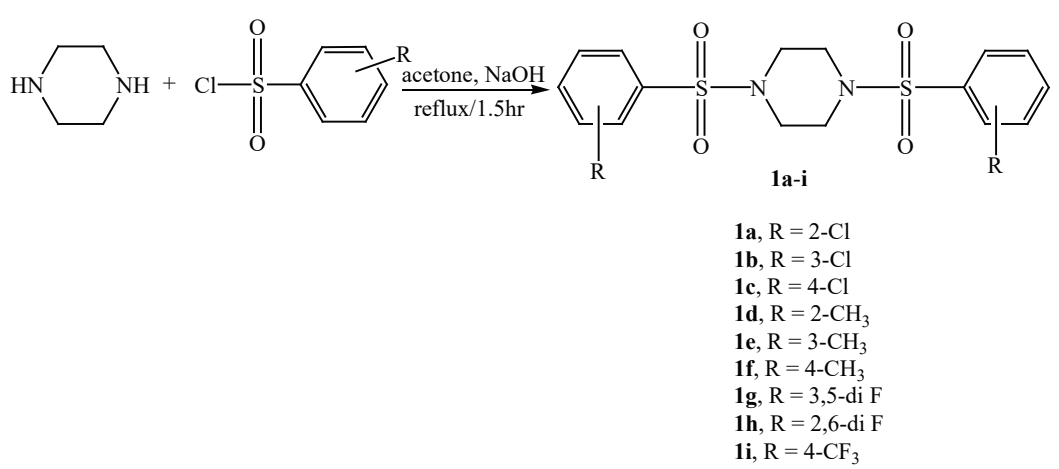

Scheme 1

three previously synthesized compounds; $\mathbf{1 d}(27), \mathbf{1 f}(27)$, and $\mathbf{1 h}(28)$ as shown in Scheme 1. Sodium hydroxide was used as an acid scavenger. The reaction was achieved by the nucleophilic addition-elimination reaction. The lone pair of electrons of the piperazine nitrogen attacks the sulfonyl group of the substituted sulfonyl chloride leading to the removal of chloride ions. Hydrochloric acid is formed in this reaction and was neutralized by sodium hydroxide (1a-e, $\mathbf{1 g}$ and $\mathbf{1 h}$ ) or by triethylamine (1f and $\mathbf{1 i})$. The reaction also took place on the second piperazine nitrogen utilizing another sulfonyl chloride molecule to create the targeted compounds 1a-i. Purification of the synthesized compounds was carried out using crystallization or column chromatography. It was found that the reaction yield was greatly enhanced when acetone and sodium hydroxide were used (1a-e, $\mathbf{1 g}$ and 1h) instead of dichloromethane and triethylamine (1f and 1i). Compound 1a was established to show a maximum yield of $76.0 \%$.

Structures of compounds 1a-i were confirmed by $\mathrm{IR},{ }^{1} \mathrm{H},{ }^{13} \mathrm{C}$ NMR and MS spectra. All spectral data are given in Table I. Piperazine hydrogen atoms in ${ }^{1} \mathrm{H}$ NMR spectra appeared as singlets at $\delta 2.99,3.02,3.05,3.08,3.11,3.15,3.20,3.24$, and $3.27 \mathrm{ppm}$ with a total number of eight hydrogens. Aromatic protons appeared at $\delta 7.19-7.90 \mathrm{ppm}$, and the coupling of the peaks was dependent on the type of the aromatic substitution whether ortho, meta or para. Methyl protons of compounds 1d-f appeared as singlets at $\delta 2.42-2.57 \mathrm{ppm}$ with a total number of six hydrogens. Piperazine carbon atoms in ${ }^{13} \mathrm{C}$ NMR spectra were located at $\delta$ $40.5-45.8$ ppm and gave the count of four carbons. Phenyl carbons appeared in the aromatic region $\delta 109.8-160.3 \mathrm{ppm}$ and gave the appropriate atom count of twelve carbons. Methyl carbons of compounds 1d-f were located at $\delta$ 20.7-21.6 ppm with a count of two carbons.

In addition, aliphatic and aromatic C-H stretching vibration bands appeared in IR spectra at 2936-2853 and 3098-3003 $\mathrm{cm}^{-1}$, resp. Aromatic C $=\mathrm{C}$ stretching vibration bands were located at $1614-1412 \mathrm{~cm}^{-1}$. Furthermore, the presence of the sulfonyl functional group was indicated by the appearance of strong stretching vibration bands at $1306-1159 \mathrm{~cm}^{-1}$.

The chemical structure of the compounds was also supported by high-resolution mass spectroscopy (HR-MS). Molecular ion peaks corresponding to the expected molecular formulas were obtained. $\mathrm{m} / \mathrm{z}$ data and the expected relative molecular masses $\left(M_{\mathrm{r}}\right)$ are given in Table I, together with other spectral and physicochemical data. IR and NMR spectra are presented in Supplementary Material. 


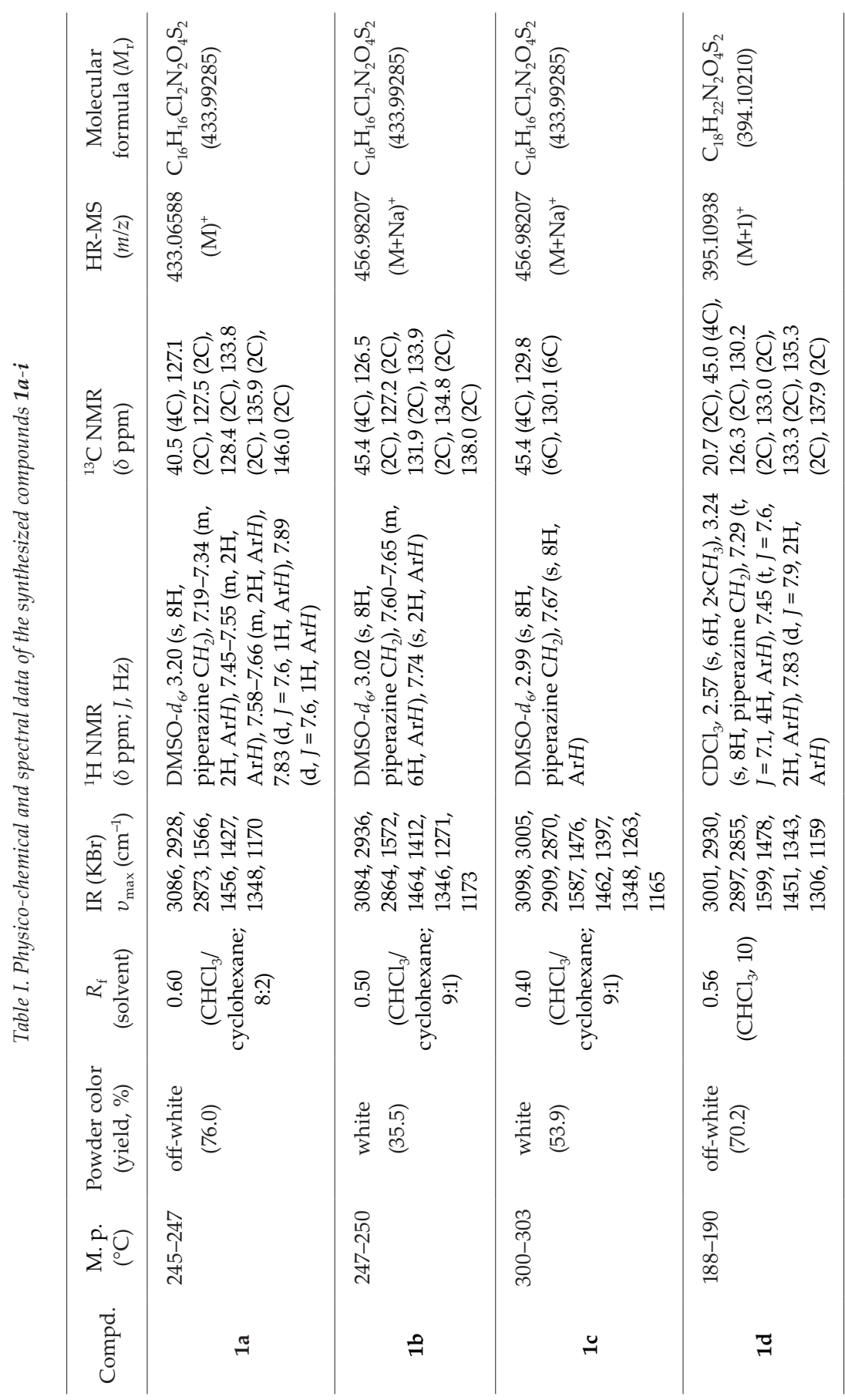




\begin{tabular}{|c|c|c|c|c|c|}
\hline 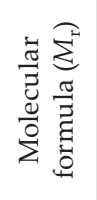 & 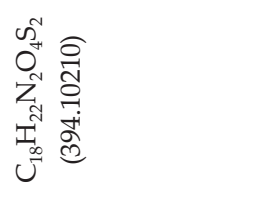 & 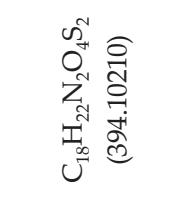 & 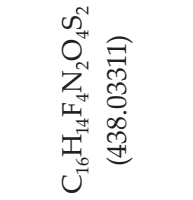 & 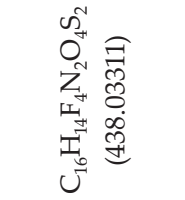 & 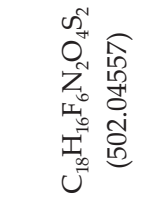 \\
\hline 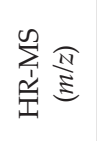 & 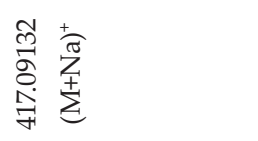 & 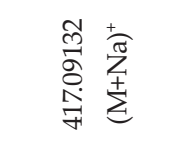 & 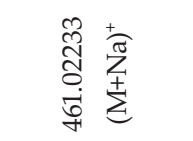 & 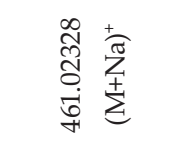 & 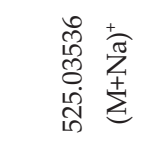 \\
\hline 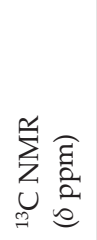 & 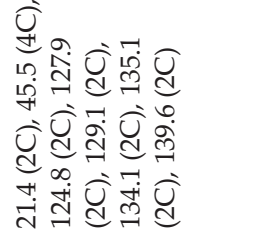 & 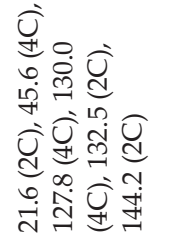 & 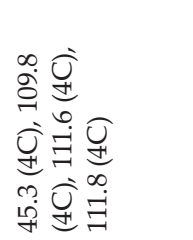 & 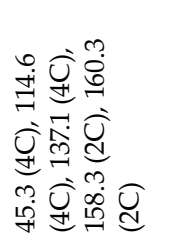 & 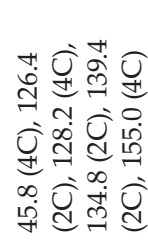 \\
\hline 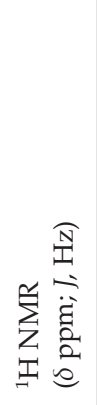 & 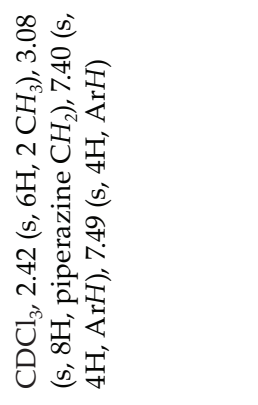 & 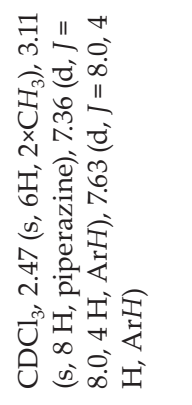 & 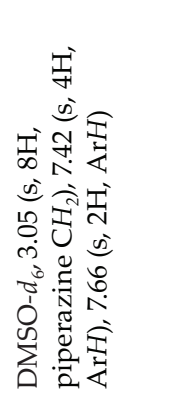 & 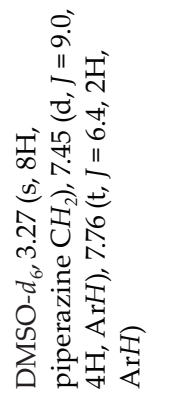 & 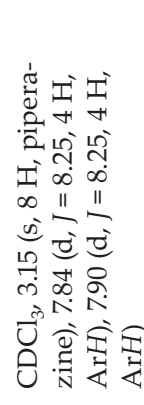 \\
\hline 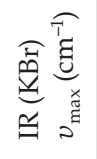 & 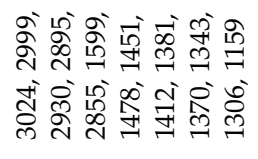 & 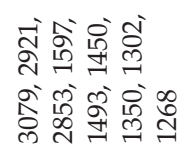 & 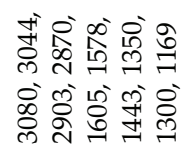 & 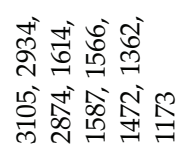 & 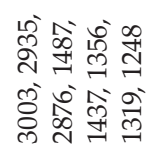 \\
\hline 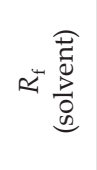 & 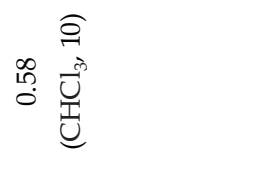 & 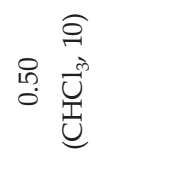 & 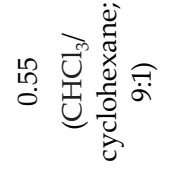 & 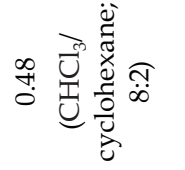 & 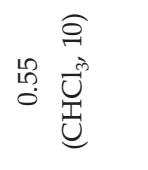 \\
\hline 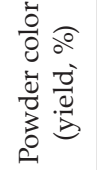 & 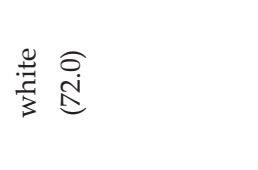 & $\frac{0}{\frac{7}{3}} \widehat{\sigma}$ & 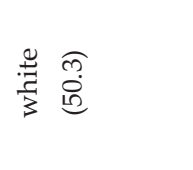 & 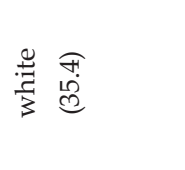 & 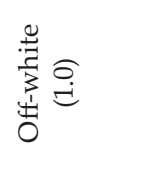 \\
\hline $\begin{array}{l}\dot{2} 0 \\
\dot{\Sigma} \theta 0\end{array}$ & 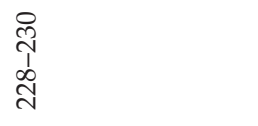 & $\begin{array}{l}\infty \\
\infty \\
\stackrel{1}{1} \\
\text { 市 }\end{array}$ & 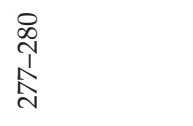 & $\begin{array}{l}\text { A } \\
\text { N } \\
\text { I } \\
\text { N }\end{array}$ & 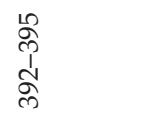 \\
\hline $\begin{array}{l}\text { ठे } \\
\text { है }\end{array}$ & $\cong$ & $\Psi$ & $\stackrel{\infty}{\rightarrow}$ & $\approx$ & 7 \\
\hline
\end{tabular}




\section{In vitro DPP-IV inhibition bioassay}

The results of in vitro DPP-IV inhibition bioassay are shown in Table II. Some of the compounds have noticeable inhibitory activity against DPP-IV at a concentration of 100 $\mu \mathrm{mol} \mathrm{L}{ }^{-1}$. The best results were found for compounds $\mathbf{1 a}, \mathbf{1} \mathbf{c}, \mathbf{1} \mathbf{h}$ and $\mathbf{1 i}$ which nearly had one-third of the inhibitory activity of the used positive control, sitagliptin, at $100 \mu \mathrm{mol} \mathrm{L}-1$.

It was noticed that ortho- and para-substituted compounds (1a, 1c, $\mathbf{1 d}, \mathbf{1 f}, \mathbf{1 h}$ and $\mathbf{1 i}$ ) either with electron-withdrawing (EWG) or electron-donating group (EDG) enhance the activity more than the meta substituted ones $(\mathbf{1 b}, \mathbf{1 e}$ and $\mathbf{1 g})$. On the other hand, the presence of two fluoro moieties at ortho-positions $(\mathbf{1 h})$ enhanced the activity more than meta groups (1g). Generally, the presence of EWG such as $\mathrm{Cl}(\mathbf{1 a}-\mathbf{c})$ improved the activity of the compounds more than EDG such as $\mathrm{CH}_{3}(\mathbf{1 d}-\mathbf{f})$ at the same positions.

\section{Computational research}

In order to investigate the binding modes of the co-crystallized ligand (N7F), sitagliptin, and the synthesized compounds 1a-i in the 4A5S binding site, we recruited induced-fit docking (IFD) against 4A5S. The IFD software investigates the conformation changes in proteins specifically; ligands are docked to a protein's binding domain implementing Glide docking $(26,29,30)$ and the highest ligand poses are minimized along with protein binding domain recruiting the Prime module (26). Consequently, a redocking protocol is performed against the relaxed protein.

IFD studies demonstrate that N7F, sitagliptin, and 1a-i occupy the 4A5S binding domain (Fig. 2a) and form H-bonding with the backbones of R125, E205, E206, F357, K554, W629, Y631, Y662, and R669 (Table III, Fig. 3 and Figs. S1-S2). Indeed, the docked pose of 1a superposes that of sitagliptin conformation (Fig. 2b). Furthermore, the significance of these residues has been detailed in experimental $(25)$ and computational $(22,23)$ studies.

It has been pointed out that compounds 1a-i show equivalent binding affinity presented by docking scores (Table III) against 4A5S. A difference in $1.73 \mathrm{kcal} \mathrm{mol}^{-1}$ between

Table II. Preliminary results for in vitro inhibition of DPP-IV by compounds $\mathbf{1} a-\mathbf{i}$

\begin{tabular}{cc}
\hline Compd. & Inhibition $(\%)^{\mathrm{a}}$ \\
\hline $\mathbf{1 a}$ & 22.6 \\
$\mathbf{1 b}$ & 13.0 \\
$\mathbf{1 c}$ & 21.5 \\
$\mathbf{1 d}$ & 17.7 \\
$\mathbf{1 e}$ & 11.2 \\
$\mathbf{1 f}$ & 15.7 \\
$\mathbf{1 g}$ & 17.0 \\
$\mathbf{1 h}$ & 21.2 \\
$\mathbf{1 i}$ & 22.3 \\
Sitagliptin & 72.8 \\
\hline
\end{tabular}

${ }^{a} 100 \mathrm{mmol} \mathrm{L}^{-1}$. Mean of duplicate repetitions. 

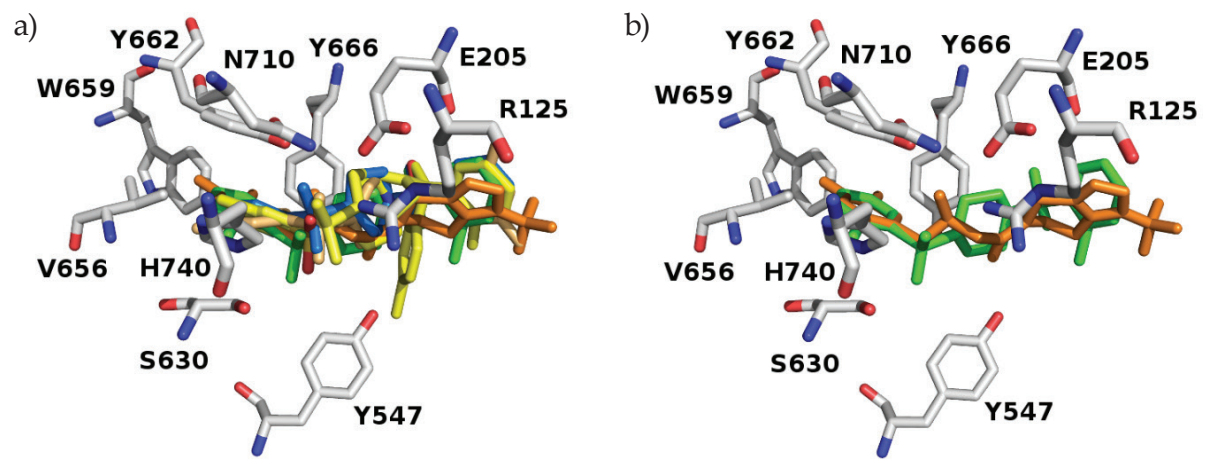

Fig. 2. a) The binding site 4 A5S accommodates IF-docked poses of N7F, sitagliptin, and 1a-i. b) Superposing of IF-docked pose of sitagliptin (orange) and 1a (green). Some of the key binding residues are declared and $H$ atoms are hidden for clarification. Picture visualized by PYMOL. E - GLU, F - PHE, H - HIS, K - LYS, N - ASN, R - ARG, S - SER, V - VAL, W - TRP, Y - TYR.

the highest and the lowest binding energy within the 1a-i series implies that compounds 1a-i demonstrate comparable binding energy towards the DPP-IV binding site. Moreover, the difference in the binding scores of N7F and sitagliptin to those of 1a-i infers that further optimization of this scaffold is needed to obtain active DPP-IV inhibitors.

In order to assess the execution of the IFD program, we compared the induced-fit docked pose of N7F in DPP-IV (PDB ID: 4A5S) (25) to its native conformation in the crystal structure. Fig. 4 shows the superposition of the IFD-produced N7F pose and native geometry in 4A5S. The relative mean square deviation (RMSD) for heavy atoms of N7F between

Table III. IFD scores against DPP-IV enzyme and H-bond interactions

\begin{tabular}{ccc}
\hline Compd. & $\begin{array}{c}\text { Docking score } \\
\left(\mathrm{kcal} \mathrm{mol}^{-1}\right)\end{array}$ & H-bond \\
\hline $\mathbf{1 a}$ & -6.85 & Y631, R669 \\
$\mathbf{1 b}$ & -6.51 & R669 \\
$\mathbf{1 c}$ & -7.08 & $\mathrm{R} 125, \mathrm{R} 669$ \\
$\mathbf{1 d}$ & -6.79 & $\mathrm{R} 669$ \\
$\mathbf{1 e}$ & -6.71 & $\mathrm{R} 125, \mathrm{~K} 554$ \\
$\mathbf{1 f}$ & -8.00 & $\mathrm{R} 669, \mathrm{~N} 710$ \\
$\mathbf{1 g}$ & -6.09 & $\mathrm{~S} 630, \mathrm{R} 669, \mathrm{~N} 710$ \\
$\mathbf{1 h}$ & -6.27 & $\mathrm{R} 125, \mathrm{~K} 554, \mathrm{~W} 629$ \\
$\mathbf{1 i}$ & -7.61 & $\mathrm{R} 125, \mathrm{~K} 554, \mathrm{~W} 629$ \\
N7F & -9.26 & $\mathrm{E} 205, \mathrm{E} 206, \mathrm{Y} 631$ \\
Sitagliptin & -10.22 & E205, E206, S209, F357, Y547, Y662 \\
\hline
\end{tabular}

E - GLU, F - PHE, IFD - induced-fit docking, K - LYS, N - ASN, R - ARG, S - SER, W - TRP, Y - TYR 
a)

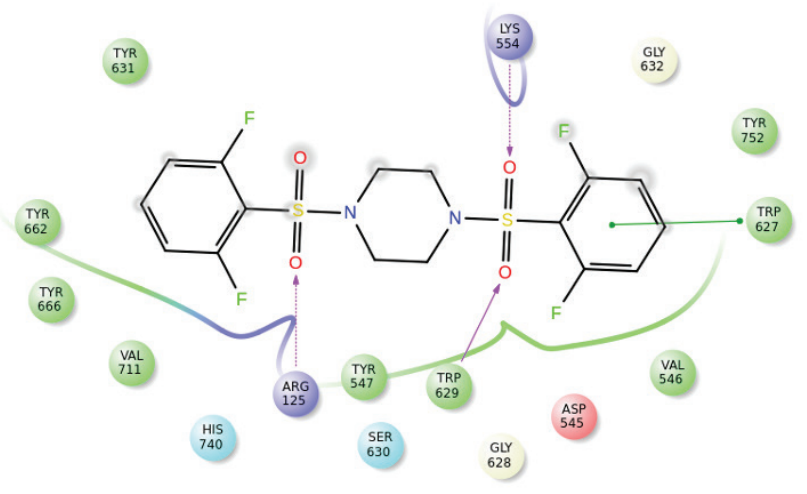

b)

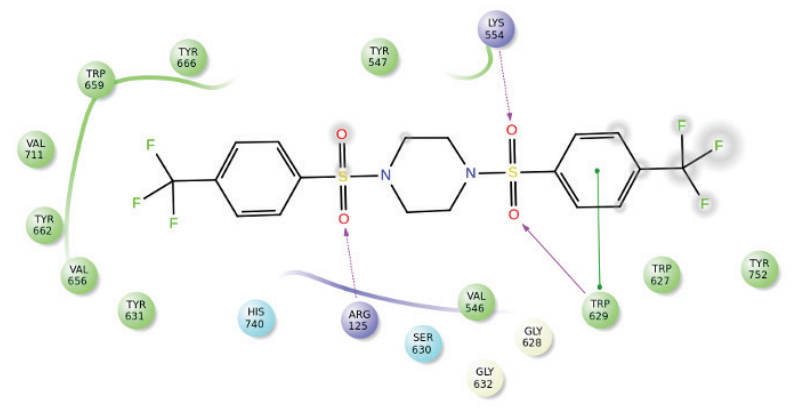

Fig. 3. Ligand/DPP-IV complex of: a) $\mathbf{1 h}$ and b) $\mathbf{1 i}$. The hydrophobic lining is colored in green, the basic residues in dark blue, acidic backbones in red, and hydrophilic in light blue.

a)

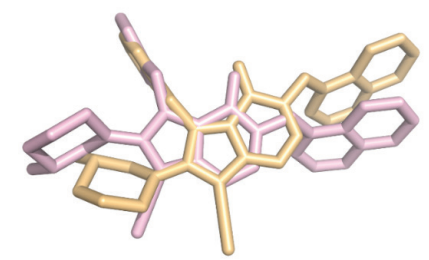

b)

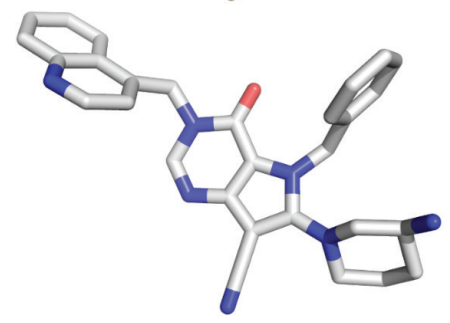

Fig. 4. a) The superposition of N7F IF docked pose and its native conformation in 4A5S. The native structure is shown in gold and the docked pose in pink. b) 2D structure of N7F. $C$ atoms are represented in grey, $\mathrm{N}$ in blue, and $\mathrm{O}$ in red color. The picture is extracted by PYMOL. 
IFD-generated docked geometry and native pose was $0.7167 \AA$. Results announce that IFD docking is capable to generate the native pose in the crystal structure and it is able to anticipate the ligand-binding geometry.

The in vitro biological data demonstrate that derivatives tailored on $o$ - or $p$-positions illustrated with 1a, 1c, $\mathbf{1 h}$, and $\mathbf{1 i}$ exerted the highest biological activity which, in fact, is comparable to each other regarding DPP-IV inhibition. Results suggest that the binding site can properly accommodate small $(\mathrm{F})(\mathbf{1} \mathbf{h})$ or large $\left(\mathrm{Cl}_{\text {or }} \mathrm{CF}_{3}\right)(\mathbf{1} \mathbf{a}, \mathbf{1 c}$, and $\mathbf{1 i})$ sized substituent in $o$ - or $p$-position.

Contrarily, analogues functionalized with $-\mathrm{CH}_{3}$ in $o$ - or $p$-position (1d and $\left.\mathbf{1 f}\right)$ exhibited lower activity reflecting that EWG displays better activity than that of EDG, and may suggest that the methyl group impedes the proper orientation of the core structure in the binding cleft. Although $-\mathrm{Cl}$ and $-\mathrm{CH}_{3}$ are bioisosteres to each other, there is a conformational restriction which orientates the analogue perfectly in the binding site. Furthermore, the difference in activity between $\mathbf{1 f}$ and $\mathbf{1} \mathbf{i}$ supports that conformational impedance influences ligand/DPP-IV complex formation.

However, the activity of $\mathbf{1 g}$ infers that $m$-substitution is not favored: the activity of $\mathbf{1 b}$ and 1e provides further evidence that $m$-attachment is disfavored.

\section{CONCLUSIONS}

In conclusion, successful synthesis and full characterization of six novel and three known piperazine sulfonamides were conducted. It was established that the compounds show prospective inhibitory activity against DPP-IV enzyme, especially compounds 1,4-bis(2-chlorophenylsulfonyl) piperazine (1a), 1,4-bis(4-chlorophenylsulfonyl) piperazine (1c), 1,4-bis(2,6-difluorophenylsulfonyl) piperazine (1h) and 1,4-bis(4-(trifluoromethyl)phenylsulfonyl) piperazine (1i). In general, it was noticed that the presence of EWG improves the activity of the compounds more than EDG at the same positions. Moreover, ortho- and para-substitution enhance the inhibitory activity, whereas meta-attachment is disfavored.

Abbreviations, acronyms, symbols. - DPP-IV - dipeptidyl peptidase-IV, EDG - electron-donating group, EWG - electron-withdrawing, GIP - glucose-dependent insulinotropic polypeptide, GLP-1 glucagon-like peptide, IFD - induced-fit docking, PDB - protein data bank, RMSD - relative mean square deviation.

Acknowledgments. - The authors acknowledge the Scientific Research Deanship at Al-Zaytoonah University of Jordan for sponsoring this project.

Supplementary materials are available upon request.

\section{REFERENCES}

1. D. Glovaci, W. Fan and N. D. Wong, Epidemiology of diabetes mellitus and cardiovascular disease, Curr. Cardiol. Rep. 21 (2019) Article ID 21 (8 pages); https://doi.org/10.1007/s11886-019-1107-y

2. N. Cho, J. Shaw, S. Karuranga, Y. Huang, D. da Rocha Fernandes, W. Ohlrogge and B. Malanda, IDF diabetes atlas: Global estimates of diabetes prevalence for 2017 and projections for 2045, Diabetes Res. Clin. Pract. 138 (2018) 271-281; https://doi.org/10.1016/j.diabres.2018.02.023 
3. A. Chaudhury, C. Duvoor, V. S. R. Dendi, S. Kraleti, A. Chada, R. Ravilla, A. Marco, N. S. Shekhawat, M. T. Montales, K. Kuriakose, A. Sasapu, A. Beebe, N. Patil, C. K. Musham, G. P. Lohani and W. Mirza, Clinical review of antidiabetic drugs: Implications for type 2 diabetes mellitus management, Front. Endocrinol. (Lausanne) 8 (Suppl 1) (2017) Article ID 6 (12 pages); https://doi.org/10.3389/fendo.2017.00006

4. N. Sergeant, V. Vingtdeux, S. Eddarkaoui, M. Gay, C. Evrard, N. Le Fur and A. Farce, New piperazine multi-effect drugs prevent neurofibrillary degeneration and amyloid deposition, and preserve memory in animal models of Alzheimer's disease, Neurobiol. Dis. 129 (2019) 217-233; https://doi.org/10.1016/j. nbd.2019.03.028

5. M. Taha, M. Irshad, S. Imran, S. Chigurupati, M. Selvaraj, F. Rahim and K. Khan, Synthesis of piperazine sulfonamide analogs as diabetic-II inhibitors and their molecular docking study, Eur. J. Med. Chem. 141 (2017) 530-537; https://doi.org/10.1016/j.ejmech.2017.10.028

6. B. R. Rao, M. R. Katiki, K. Dileep, C. G. Kumar, G. N. Reddy, J. B. Nanubolu and M. S. R. Murty, Synthesis and biological evaluation of benzothiazole-piperazine-sulfonamide conjugates and their antibacterial and antiacetylcholinesterase activity, Lett. Org. Chem. 16 (2019) 723-734; https://doi.org/10. 2174/1570178615666181113094539

7. D. C. Martyn, J. F. Cortese, E. Tyndall, J. Dick, R. Mazitschek, B. Munoz and J. Clardy, Antiplasmodial activity of piperazine sulfonamides, Bioorg. Med. Chem. Lett. 20 (2010) 218-221; https://doi. org/10.1016/j.bmcl.2009.10.130

8. C. J. Bungard, P. D. Williams, J. Schulz, C. M. Wiscount, M. K. Holloway, H. M. Loughran and X. J. $\mathrm{Chu}$, Design and synthesis of piperazine sulfonamide cores leading to highly potent HIV-1 protease inhibitors, ACS Med. Chem. Lett. 8 (2017) 1292-1297; https:// doi.org/10.1021\%2Facsmedchemlett. $7 \mathrm{~b} 00386$

9. R. Thoma, B. Löffler, M. Stihle, W. Huber, A. Ruf and M. Hennig, Structural basis of proline-specific exopeptidase activity as observed in human dipeptidyl peptidase-IV, Structure 11 (2003) 947-959; https://doi.org/10.1016/s0969-2126(03)00160-6

10. C. Deacon, Physiology and pharmacology of DPP-4 in glucose homeostasis and the treatment of type 2 diabetes, Front. Endocrinol. (Lausanne) 10 (2019) Article ID 80 (14 pages); https://doi.org/10.3389/ fendo.2019.00080

11. S. Q. Pantaleão, E. A. Philot, P. T. de Resende-Lara, A. N. Lima, D. Perahia, M. Atanassova Miteva, A. L. Scott and K. M. Honorio, structural dynamics of dpp-4 and its influence on the projection of bioactive ligands, Molecules 23 (2018) Article ID 490 (10 pages); https://doi.org/10.3390/molecules23020490

12. O. Power-Grant, A. B. Nongonierma, P. Jakeman and R. J. FitzGerald, Food protein hydrolysates as a source of dipeptidyl peptidase IV inhibitory peptides for the management of type 2 diabetes, Proc. Nutr. Soc. 73 (2014) 34-46; https://doi.org/10.1017/S0029665113003601

13. M. Sano, Mechanism by which dipeptidyl peptidase-4 inhibitors increase the risk of heart failure and possible differences in heart failure risk, J. Cardiol. 73 (2018) 28-32; https://doi.org/10.1016/j. jjcc.2018.07.004

14. Y. Nakamaru, F. Akahoshi, H. Iijima, N. Hisanaga and T. Kume, Tissue distribution of teneligliptin in rats and comparisons with data reported for other dipeptidyl peptidase-4 inhibitors, Biopharm. Drug Dispos. 37 (2016) 142-155; https://doi.org/10.1002\%2Fbdd.2003

15. R. N. Kushwaha, W. Haq and S. B. Katti, Sixteen-years of clinically relevant dipeptidyl peptidase-IV (DPP-IV) inhibitors for treatment of type-2 diabetes: a perspective, Curr. Med. Chem. 21 (2014) 40134045; https://doi.org/10.2174/0929867321666140915143309

16. V. Gupta and S. Kalra, Choosing a gliptin, Indian J. Endocrinol. Metab 15 (2011) 298-308; https:// doi. org $/ 10.4103 \% 2$ F2230-8210.85583

17. J. Shubrook, R. Colucci, A. Guo and F. Schwartz, Saxagliptin: A selective DPP-4 inhibitor for the treatment of type 2 diabetes mellitus, Clin. Med. Insights Endocrinol. Diabetes 4 (2011) 1-12; https://doi. org/10.4137/CMED.S5114 
18. T. Kadowaki and K. Kondo, Efficacy and safety of teneligliptin in combination with pioglitazone in Japanese patients with type 2 diabetes mellitus, J. Diabetes Investig. 4 (2013) 576-584; https://doi. org/10.1111/jdi.12092

19. T. Kadowaki and K. Kondo, Efficacy and safety of teneligliptin added to glimepiride in Japanese patients with type 2 diabetes mellitus: a randomized, double-blind, placebo-controlled study with an open-label, long-term extension, Diabetes Obes. Metab. 16 (2014) 418-425; https://doi.org/10.1111/ dom.12235

20. C. F. Deacon, Dipeptidyl peptidase- 4 inhibitors in the treatment of type 2 diabetes: a comparative review, Diabetes Obes. Metab. 13 (2011) 7-18; https://doi.org/10.1111/j.1463-1326.2010.01306.x

21. R. Abu Khalaf, G. Abu Sheikha, M. Al-Sha'er and M. Taha, Design, synthesis and biological evaluation of $N^{4}$-sulfonamido-succinamic, phthalamic, acrylic and benzoyl acetic acid derivatives as potential DPP IV inhibitors, Open Med. Chem. J. 7 (2013) 39-48; https://doi.org/10.2174/1874104501307010039

22. R. Abu Khalaf, Z. Jarekji, T. Al-Qirim, D. Sabbah and G. Shattat, Pharmacophore modeling and molecular docking studies of acridines as potential DPP-IV inhibitors, Can. J. Chem. 93 (2015) 721-729; https://doi.org/10.1139/cjc-2015-0039

23. R. Abu Khalaf, D. Sabbah, E. Al-Shalabi, I. Al-Sheikh, G. Albadawi and G. Abu Sheikha, Synthesis, structural characterization and docking studies of sulfamoyl-phenyl acid esters as dipeptidyl peptidase-IV inhibitors, Curr. Comput. Aid. Drug Des. 14 (2018) 142-151; https://doi.org/10.2174/15734099146 66180308164013

24. R. A. Khalaf, D. Masalha and D. Sabbah, DPP-IV inhibitory phenanthridines: Ligand, structurebased design and synthesis, Curr. Comput. Aid. Drug Des. 16 (2020) 295-307; https://doi.org/10.2174/15 73409915666181211114743

25. J. M. Sutton, D. E. Clark, S. J. Dunsdon, G. Fenton, A. Fillmore, N. V. Harris, C. Higgs, C. A. Hurley, S. L. Krintel, R. E. MacKenzie, A. Duttaroy, E. Gangl, W. Maniara, R. Sedrani, K. Namoto, N. Ostermann, B. Gerhartz, F. Sirockin, J. Trappe, U. Hassiepen and D. K. Baeschlin, Novel heterocyclic DPP4 inhibitors for the treatment of type 2 diabetes, Bioorg. Med. Chem. Lett. 22 (2012) 1464-1468; https:// doi.org/10.1016/j.bmcl.2011.11.054

26. Protein Preparation Wizard, Maestro, Macromodel, QPLD-dock and Pymol, Schrödinger, LLC, Portland (OR), 2016; https://www.schrodinger.com/, last access July, 2020

27. M. Smith and C. Pollard, New compounds. Derivatives of piperazine. XIX. Reactions with aryl sulfonyl chlorides and aryl sulfonic acids, J. Am. Chem. Soc. 63 (1941) 630-631; https://pubs.acs.org/doi/ abs/10.1021/ja01847a076

28. M. B. Boxer, J. Jiang, M. G. Vander Heiden, M. Shen, A. P. Skoumbourdis, N. Southall, H. Veith, W. Leister, C. P. Austin, H. Won Park, J. Inglese, L. C. Cantley, D. S. Auld and C. J. Thomas, Evaluation of substituted $N, N^{\prime}$-diarylsulfonamides as activators of the tumor cell specific M2 isoform of pyruvate kinase, J. Med. Chem. 53 (2010) 1048-1055; https://pubs.acs.org/doi/10.1021/jm901577g

29. R. A. Friesner, J. L. Banks, R. B. Murphy, T. A. Halgren, J. J. Klicic, D. T. Mainz, M. P. Repasky, E. H. Knoll, M. Shelley, J. K. Perry, D. E. Shaw, P. Francis and P. S. Shenkin, Glide: A new approach for rapid, accurate docking and scoring. 1. Method and assessment of docking accuracy, J. Med. Chem. 47 (2004) 1739-1749; https://doi.org/10.1021/jm0306430

30. R. A. Friesner, R. B. Murphy, M. P. Repasky, L. L. Frye, J. R. Greenwood, T. A. Halgren, P. C. Sanschagrin and D. T. Mainz, Extra precision glide: Docking and scoring incorporating a model of hydrophobic enclosure for protein-ligand complexes, J. Med. Chem. 49 (2006) 6177-6196; https://doi. org/10.1021/jm051256o 